\title{
Reflections versus Extended Quizzes: Which is Better for Student Learning and Self- Regulation?
}

\author{
Virginia Clinton \\ University of North Dakota \\ Virginia.clinton@und.edu
}

\begin{abstract}
Both quizzes and reflections have been found to benefit student learning, but have been typically compared to passive or superficial controls. The purpose of this quasi-experiment is to test the relative effectiveness of brief quizzes followed by reflections compared to longer quizzes. Participants $(N=218)$ were introductory psychology students enrolled in two different courses, one in which students engaged in weekly brief quizzes and reflections and a second in which students engaged in longer quizzes. Results indicated that the two conditions were similar in effectiveness in terms of learning and self-reports of self-regulation.
\end{abstract}

Keywords: Quiz, reflection, instructional design, self-regulation

\section{Introduction}

Instructors who are committed to improving student learning often review the literature and find that many instructional methods may improve student study strategies and subsequent learning. For examples, writing reflections and quizzes have both been shown to be effective methods of increasing learning (e.g., McDaniel, Agarwal, Huelser, McDermott, \& Roediger, 2011; Watkins, 2001). However, the benefits of these instructional methods are typically compared to passive controls (e.g., Angus \& Watson, 2009; Bannert, 2006; Connor-Greene, 2000; Moos \& Bonde, 2015; see Di Stefano, Gino, Pisano, \& Staats, 2014 for an exception). Instructional time and student study time are limited, so it would be useful for instructors to know which technique is more effective in an authentic class environment. The purpose of this study is to compare the relative benefits of reflection versus extended practice in a college course.

Benefits of Quizzes

Incorporating quizzes, which are frequent, low stakes learning assessments, has been noted to benefit performance in a variety of disciplines (e.g., Angus \& Watson, 2009; McDaniel, Wildman, \& Anderson, 2012). Quizzes are thought to be helpful for several reasons under the framework of desirable difficulties (Bjork, Little, and Storm, 2014). Desirable difficulties are challenges that benefit students by improving encoding and processes that support learning (Bjork \& Bjork, 2011). Quizzes provide an opportunity for students to practice retrieving and using information from memory (McDaniel et al., 2011). This practice retrieval is beneficial because it can strengthen long-term memory of the material (Roediger \& Butler, 2011; Roediger $\&$ Karpicke, 2008). In addition, students often overestimate how well they understand content, a phenomenon known as the illusion of competence (Koriat \& Bjork, 2005). One way to overcome the illusion of competence is to have students test themselves on the content (Kornell \& Bjork, 2007). Unfortunately, students often choose to reread material than to quiz themselves (Karpicke, Butler, \& Roediger, 2009) even though rereading material is considered an ineffective 
learning strategy (see Dunlosky, Rawson, Marsh, Nathan, \& Willingham, 2013). For these reasons, requiring quizzes may be helpful for students to improve the monitoring of their learning. Finally, if quizzes occurred frequently throughout a term, they encourage students to study and review the material regularly (i.e., spaced practice) instead of relying on last-minute exam preparation (i.e., massed practice; Connor-Greene, 2000; McDaniel, Roediger, \& McDermott, 2007).

\section{Benefits of Reflection}

Reflection, the process of examining and contemplating one's knowledge and learning, has also been noted as beneficial for student learning (Dewey, 1933; Peltier, Hay, \& Drago, 2005; Rogers, 2001). Reflection provides opportunities to think about performance, consider what strategies are effective, and contemplate how to improve in the future (Mann, Gordeon, \& MacLeod, 2009). Reflection is a key process in effectively choosing and monitoring strategies to achieve one's goals, known as self-regulation (Dabbagh \& Kitsantas, 2004; Ellis \& Davidi, 2005). Specifically, reflection is critical to monitoring behaviors during a task and evaluating the effectiveness of these behaviors (Nussbaumer, Dahn, Kroop, Mikroyanndis, \& Albert, 2015). Moreover, self-regulation can be taught with reflections (Paris \& Paris, 2001). For these reasons, reflection can improve learning by making it intentional and purposeful (Di Stefano et al., 2015). This is likely why empirical evidence indicates learning benefits with reflections (see Zheng, 2016 for review). For examples, reflections on learning strategies used for mathematics assignments lead to improved course performance (Zimmerman, Moylan, Hudesman, White, \& Flugman, 2011). In addition, reflecting on learning strategies improved students' skills to develop their own knowledge (Cacciamani, Cesareni, Martini, Ferrini, \& Fujita, 2012). Moreover, prompts to reflect on one's learning process improve performance on transfer tasks (Bannet, 2006; Bannert \& Reimann, 2012). In work contexts, individuals who engaged in reflection had lower error rates when learning work skills than their less reflective peers (Roessger, 2014). Finally, choosing to engage in reflective thinking practices is positively associated with academic performance (Phan, 2014).

\section{The Current Study}

The discussion on quizzes and reflections indicate that both may improve student learning. However, the amount of time students are willing to apply towards a course is finite.

Given restraints, is it better to answer more quiz questions thereby covering more content related to exams or to have a shorter quiz followed by a reflection on learning? The current study addresses this question with a quasi-experiment using two large introductory psychology courses. One course had quizzes followed by a reflection on how they learned the material. The other course had a longer quiz, but no reflection. Because reflection is most effective when regular and ongoing throughout the semester (Bringle \& Hatcher, 1999), quizzes and reflections were weekly.

The current study examined the relative effects of quizzes and reflections versus extended quizzing on two sets of dependent variables: performance on exams and self-reported selfregulation. Performance on exams was chosen because it is indicative of overall learning in the course and the variable of interest in class-based quiz studies (e.g., Rezaei, 2015). Self-regulation was of interest to allow for examination into possible changes during the semester as a result of 
reflections. If the results of the current study indicate that reflection benefited performance compared to extended quizzing, it is likely because reflection improved self-regulation.

Typically, studies on quizzes compared conditions with quizzes to control conditions without a comparable learning activity (e.g., Angus \& Watson, 2009; Bjork et al., 2014; ConnorGreene, 2000; although often conditions varying the types of quizzes were also compared; e.g., Bunce, VandenPlas, \& Havanki, 2006; McDaniel et al., 2011) or quizzes were compared to an ineffective study strategy, such as rereading (McDaniel et al., 2012; McDermott et al., 2014). Moreover, reflection studies typically used passive controls in which students were not given reflection prompts (e.g., Bannert, 2006; Moos \& Bonde, 2015; although there may be comparisons in the types of reflection activities as well; e.g., Michalsky \& Kramarski, 2015; Roessger, 2014). In contrast, the relative benefits of brief practice followed by a reflection versus extended practice without reflection on mathematical tasks were compared in a lab experiment (Di Stefano et al., 2015). Findings from this work indicated that, although individuals indicated a preference for extended practice over reflection, performance improved with reflection compared to extended practice. Based on these findings, it is likely that reflection would lead to better study strategies and course performance in the current study than would extended quizzes. However, lab results do not necessarily transfer to class environments (see Hulleman \& Cordray, 2009). This may be especially true when considering the work by Stefano and colleagues as they examined performance on a single mathematical skill whereas the current study examined performance on understanding a broad range of psychological concepts.

\section{Methods}

\section{Participants}

Participants were 218 introductory psychology students at a large Midwestern university. Only students who completed at least $75 \%$ of the quizzes and/or reflections (depending on condition) and completed both pre- and post- self-regulation measures (see Measures) were included in analyses. Approximately $60 \%$ of the students identified as female and $40 \%$ identified as male with an average age of 19.02 years ( $\mathrm{SD}=1.89$ years). In terms of racial background, approximately 86\% reported being Caucasian, 2\% reported being African American, 4\% reported being Asian, 1\% reported being Hispanic, 3\% reported being biracial or multiracial, and the remainder did not report racial background.

\section{Procedure}

Participants were in two different courses, both taught by the same instructor and both offered in the afternoon. The lectures and exams were the same in both courses. For the course in the quizand-reflection condition, students completed a 5-item, multiple-choice quiz weekly followed by a reflection of how they learned the material for the quiz. Following exams, students reflected on how they learned the material for the exam. For the course in the extended quizzing condition, students completed a 10 -item (5 of the items were the same as in the quiz-and-reflection condition), multiple-choice quiz weekly. Information targeted by the quizzes was either on the exams or related to information on the exams. There were 104 participants in the extended quizzing condition and 114 in the quiz-and-reflection condition. All weekly assignments were completed online through the course learning management site. Students were given immediate 
feedback on their quiz performance. Following best practices in teaching with reflections, reflections were given feedback as well (Aronson, 2011). Only students who completed at least $75 \%$ of the quizzes and/or reflections (depending on condition) were included in analyses.

At the beginning of the semester, students in both courses learned about effective and ineffective study strategies as part of the cognitive psychology unit. In addition, students were required to read and write a response to a systematic review of study strategies written by Dunlosky and colleagues (2013) at the beginning of the semester. Therefore, they had a background in study strategies upon which to reflect.

\section{Measures}

Three unit exams were the measures of course performance. Unit exams were not cumulative. There was also an optional final exam (students could choose to take the final exam to replace a previous, lower unit exam grade) that 112 students chose to take. The final exam was cumulative. Each exam consisted of 40 multiple-choice questions.

The Metacognitive Self-Regulation Scale (MLSQ; 12 items) from the Motivated Strategies for Learning Questionnaire was used to measure self-regulation (Pintrich, Smith, Garcia, \& McKeachie, 1993). The MSLQ has been used in many research studies and is considered a useful, flexible tool for examining the differential effects of interventions (Duncan \& McKeachie, 2005). It was administered to students in class during the second week of the semester and the second-to-last week of the semester.

\section{Results}

To compare the relative effectiveness of the quiz-and-reflection condition versus the extendedquiz condition on performance, the effects of condition on both the sum of the unit exams scores and the final exam score were examined. First, a one-way ANOVA was conducted with condition as the independent variable and the number of items answered correctly on the three unit exams as the dependent variable. There was no difference between conditions, $F(1,217)=$ $1.07, p=.30$ (see Figure 1).

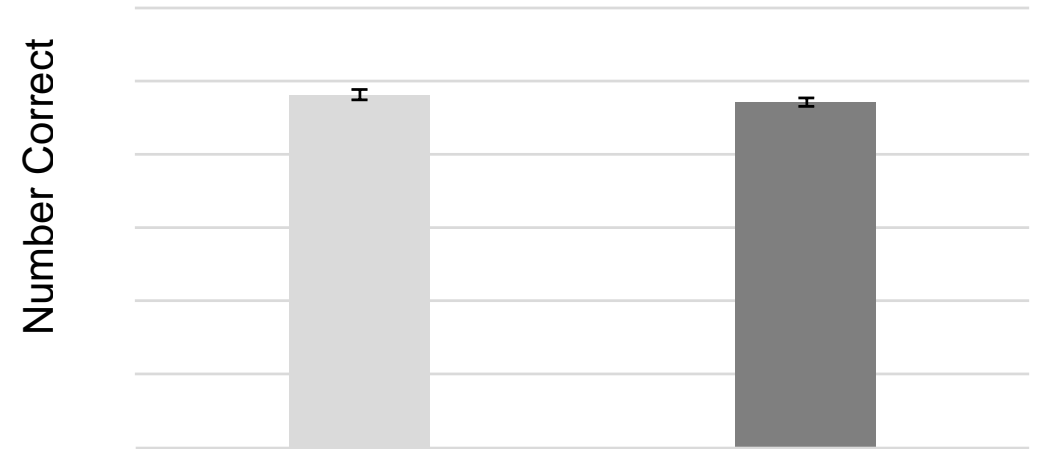

Figure 1: Unit exam scores by condition (means and $+/-1$ standard error bars) 
Then, a one-way ANCOVA was conducted with condition as the independent variable, the number of items answered correctly on the final exam as the dependent variable, and number of items answered correctly on the three previous unit exams as the dependent variable. Again, there was no difference between conditions on exam performance, $F(1,110)=.20, p=.65$ (see Figure 2). Previous exam performance was a significant covariate, $F(1,110)=174.61, p<.001$.

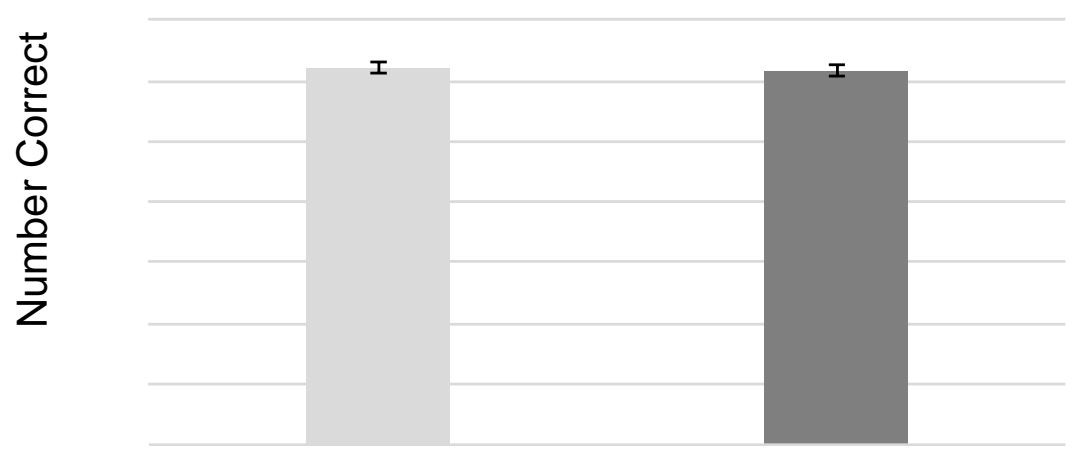

Figure 2: Final exam scores by condition (covariate adjusted means and $+/-1$ standard error bars)

The relative effectiveness of the conditions on metacognitive self-regulation was also examined. A one-way ANCOVA was conducted with condition as the independent variable, scale score at the beginning of the semester as a covariate, and scale score at the end of the semester as the dependent variable. There was no difference between condition, $F(216)=.04, p$ $=.84$ (see Figure 3 ). Scale score at the beginning of the semester was significant as a covariate, $F(1,216)=127.03, p<.001$.

Figure 3: Metacognitive self-regulation scores by condition (covariate adjusted means and $+/-$ 1 standard error bars) 


\section{Discussion}

The purpose of this study was to compare the relative benefits of a brief quiz followed by a learning reflection versus an extended quiz. Based on the findings from this study, there was no difference in the two instructional methods on student learning or self-regulation.

These findings may be informative for instructional design. For example, an instructor who wishes to incorporate reflections, but is concerned that less content would be covered as a result, may find these findings reassuring that covering less content in quizzes may not lead to less learning in a course. Conversely, an instructor who teaches large enrollment courses with minimal assistance for grading may appreciate knowing that longer quizzes, which may be automatically graded with feedback through learning management systems, may be as useful as reflections, which may be labor intensive to grade.

\section{Limitations and Future Directions}

Given that both quizzes and reflections have been previously found to improve learning (e.g., McDaniel et al., 2012; Di Stefano et al., 2015), it was not surprising that there was no difference in exam performance between the two courses. However, it was anticipated that reflection would increase self-regulation given previous findings (Dabbagh \& Kitsantas, 2004; Paris \& Paris, 2001; De Steafno et al., 2015). One reason for the similar self-regulation scores between conditions could be that the extended quizzes prompted the students to self-regulate as they had to apply their learning strategies to more content than did students in the quiz-and-reflection condition. Another possibility is that reflection prompted enhanced self-regulation more than extended quizzing, but that the self-report measure was not sufficiently detailed to detect a difference. An interesting idea for future work would be a mixed methods approach and, in addition to the quantitative data from the self-reports, obtain qualitative data by interviewing a sample of students about how they regulate their learning and how quizzing and reflection contribute to self-regulation. The findings from such a study would provide information of both breadth and depth to illuminate the relationships between these instructional methods and selfregulation.

One important limitation of the design in this study is that a control condition without quizzes or reflections was not incorporated. However, such a condition was considered unnecessary. There did not appear to be a need to conduct another empirical study showing that quizzes and/or reflections yielded learning benefits over a passive control or a control with an ineffective study strategy (e.g., rereading). Moreover, it could be considered unfair to students in a control condition to deprive them of an instructional method shown to be effective in the literature. Overall, the design of this study, a quasi-experiment comparing two techniques previously found to be effective, afforded practical guidance for instructors to make decisions about their courses. Given the number of instructional methods found to have benefits over passive or superficial controls, it may be helpful for future studies to compare the relative effectiveness of instructional methods to help instructors determine which methods are most effective.

\section{Conclusion}


Instructors who wish to incorporate research-based practices into their courses may be overwhelmed by the number of methods noted as effective in the scholarship of teaching and learning literature. To help instructors make informed choices, this manuscript discusses a study in which the relative effectiveness of two instructional methods-quizzing and reflections-are assessed in a quasi-experiment. Although the results indicated similar scores on learning and self-regulation measures for the two methods, these findings provide guidance for instructors. Instructors can apply these findings to know that quizzes and reflections appear to be equally effective and base their decision on what would work best for their particular learning environments.

\section{Acknowledgements}

Courtney Duff, Alex Karie, and Alek Krumm are thanked for their assistance with data collection and entry.

\section{References}

Angus, S. D., \& Watson, J. (2009). Does regular online testing enhance student learning in the numerical sciences? Robust evidence from a large data set. British Journal of Educational Technology, 40(2), 255-272. http://doi.org/10.1111/j.1467-8535.2008.00916.X

Aronson, L. (2011). Twelve tips for teaching reflection at all levels of medical education. Medical Teacher, 33(3), 200-205. https://doi.org/10.3109/0142159X.2010.507714

Bannert, M. (2006). Effects of reflection prompts when learning with hypermedia. Journal of Educational Computing Research, 35(4), 359-375. https://doi.org/10.2190/94V6-R58H-3367G388

Bannert, M., \& Reimann, P. (2012). Supporting self-regulated hypermedia learning through prompts. Instructional Science, 40(1), 193-211. https://doi.org/10.1007/s11251-011-9167-4

Bjork, E.L., \& Bjork, R.A. (2011) Making things hard on yourself, but in a good way: Creating desirable difficulties to enhance learning. Psychology and the real world: Essays illustrating fundamental contributions to society, (Eds.) M.A. Gernsbacher, R.W. Pew, L.M. Hough, J.R. Pomerantz, pp. 56-64. Worth: New York.

Bjork, E. L., Little, J. L., \& Storm, B. C. (2014). Multiple-choice testing as a desirable difficulty in the classroom. Journal of Applied Research in Memory and Cognition, 3(3), 165-170. https://doi.org/10.1016/j.jarmac.2014.03.002

Bunce, D. M., VandenPlas, J. R., \& Havanki, K. L. (2006). Comparing the effectiveness on student achievement of a student response system versus online WebCT quizzes. Journal of Chemical Education, 83(3), 488. https://doi.org/10.1021/ed083p488

Bringle, R. G., \& Hatcher, J. A. (1999, Summer). Reflection is service-learning: Making meaning of experience. Educational Horizons, 179-185. Retrieved from http://digitalcommons.unomaha.edu/cgi/viewcontent.cgi?article=1024\&context=slceeval 
Cacciamani, S., Cesareni, D., Martini, F., Ferrini, T., \& Fujita, N. (2012). Influence of participation, facilitator styles, and metacognitive reflection on knowledge building in online university courses. Computers \& Education, 58(3), 874-884.

https://doi.org/10.1016/j.compedu.2011.10.019

Connor-Greene, P. A. (2000). Assessing and promoting student learning: Blurring the line between teaching and testing. Teaching of Psychology, 27(2), 84-88.

https://doi.org/10.1207/S15328023TOP2702_01

Dabbagh, N., \& Kitsantas, A. (2004). Supporting self-regulation in student-centered web-based learning environments. International Journal on E-learning, 3(1), 40-47. Retrieved from http://www.learntechlib.org/p/4104

Dewey, J. 1933. How we think: A restatement of the relation of reflective thinking to the education process. Boston: D. C. Health.

Di Stefano, G., Gino, F., Pisano, G. P., \& Staats, B. R. (2014, March 25). Learning by thinking: How reflection aids performance. Harvard Business School Working Paper Series. Retrieved from http://hbswk.hbs.edu/item/learning-by-thinking-how-reflection-improves-performance

Duncan, T. G., \& McKeachie, W. J. (2005). The making of the motivated strategies for learning questionnaire. Educational Psychologist, 40(2), 117-128.

https://doi.org/10.1207/s15326985ep4002_6

Dunlosky, J., Rawson, K. A., Marsh, E. J., Nathan, M. J., \& Willingham, D. T. (2013). Improving students' learning with effective learning techniques promising directions from cognitive and educational psychology. Psychological Science in the Public Interest, 14(1), 4-58. https://doi.org/10.1177/1529100612453266

Ellis, S., \& I. Davidi. 2005. After-event reviews: Drawing lessons from successful and failed experience. Journal of Applied Psychology, 90, 857-871. https://doi.org/10.1037/00219010.90.5.857

Fruhmann K, Nussbaumer A, Albert D. (2010). A psycho-pedagogical framework for selfregulated learning in a responsive open learning environment. In S. Hambach, A. Martens, D. Tavangarian , B. Urban, (Eds.). Proceedings of the international conference eLearning Baltics science (eLBa Science 2010). Rostock: Fraunhofer. Retrieved from http://csskti.tugraz.at/research/cssarchive/staff/nussbaumer/pubfiles/ELBA2010-SRLFramework.pdf

Hulleman, C. S., \& Cordray, D. S. (2009). Moving from the lab to the field: The role of fidelity and achieved relative intervention strength. Journal of Research on Educational Effectiveness, 2(1), 88-110. https://doi.org/10.1080/19345740802539325

Karpicke, J. D., Butler, A. C., \& Roediger III, H. L. (2009). Metacognitive strategies in student learning: do students practise retrieval when they study on their own? Memory, 17(4), 471-479. https://doi.org/10.1080/09658210802647009 
Kornell, N., \& Bjork, R. A. (2007). The promise and perils of self-regulated study. Psychonomic Bulletin \& Review, 14(2), 219-224. https://doi.org/10.3758/BF03194055

Koriat, A., \& Bjork, R. A. (2005). Illusions of competence in monitoring one's knowledge during study. Journal of Experimental Psychology: Learning, Memory, and Cognition, 31(2), 187. https://doi.org/10.1037/0278-7393.31.2.187

Mann, K., Gordon, J., \& MacLeod, A. (2009). Reflection and reflective practice in health professions education: A systematic review. Advances in Health Sciences Education, 14(4), 595621. https://doi.org/10.1007/s10459-007-9090-2

McDaniel, M. A., Agarwal, P. K., Huelser, B. J., McDermott, K. B., \& Roediger, H. I. (2011). Test-enhanced learning in a middle school science classroom: The effects of quiz frequency and placement. Journal of Educational Psychology, 103(2), 399-414.

https://doi.org/10.1037/a0021782

McDaniel, M. A., Thomas, R. C., Agarwal, P. K., McDermott, K. B., \& Roediger, H. L. (2013). Quizzing in middle-school science: Successful transfer performance on classroom exams. Applied Cognitive Psychology, 27(3), 360-372. https://doi.org/10.1002/acp.2914

McDaniel, M. A., Wildman, K. M., \& Anderson, J. L. (2012). Using quizzes to enhance summative-assessment performance in a web-based class: An experimental study. Journal of Applied Research in Memory and Cognition, 1(1), 18-26.

https://doi.org/10.1016/j.jarmac.2011.10.001

McDaniel, M. A., Roediger, H. L., \& McDermott, K. B. (2007). Generalizing test-enhanced learning from the laboratory to the classroom. Psychonomic Bulletin \& Review, 14(2), 200-206. https://doi.org/10.3758/BF03194052

Moos, D. C., \& Bonde, C. (2015). Flipping the classroom: Embedding self-regulated learning prompts in videos. Technology, Knowledge and Learning, 1-18. https://doi.org/10.1007/s10758015-9269-1

Nussbaumer, A., Dahn, I., Kroop, S., Mikroyannidis, A., \& Albert, D. (2015). Supporting selfregulated learning. In Responsive Open Learning Environments (pp. 17-48). Springer International Publishing. https://doi.org/10.1007/978-3-319-02399-1_2 Paris, S. G., \& Paris, A. H. (2001) Classroom Applications of Research on Self-Regulated Learning, Educational Psychologist, 36(2), 89-100. https://doi.org/10.1207/S15326985EP3602_4

Peltier, J. W., Hay, A., \& Drago, W. (2005). The reflective learning continuum: Reflecting on reflection. Journal of Marketing Education, 27(3), 250-263.

https://doi.org/10.1177/0273475305279657 
Phan, H. P. (2014). Self-efficacy, reflection, and achievement: A short-term longitudinal examination. The Journal of Educational Research, 107(2), 90-102.

https://doi.org/10.1080/00220671.2012.753860

Pintrich, P. R., Smith, D. A., García, T., \& McKeachie, W. J. (1993). Reliability and predictive validity of the Motivated Strategies for Learning Questionnaire (MSLQ). Educational and Psychological Measurement, 53(3), 801-813. https://doi.org/10.1177/0013164493053003024

Rezaei, A. R. (2015). Frequent collaborative quiz taking and conceptual learning. Active Learning in Higher Education, 16(3), 187-196. https://doi.org/10.1177/1469787415589627

Roediger, H. L., \& Butler, A. C. (2011). The critical role of retrieval practice in long-term retention. Trends in Cognitive Sciences, 15(1), 20-27. https://doi.org/10.1016/j.tics.2010.09.003

Roediger, H. L., \& Karpicke, J. D. (2006). The power of testing memory: Basic research and implications for educational practice. Perspectives on Psychological Science, 1(3), 181-210. https://doi.org/10.1111/j.1745-6916.2006.00012.x

Rogers, R. R. (2001). Reflection in higher education: A concept analysis. Innovative Higher Education, 26(1), 37-57. https://doi.org/10.1023/A:1010986404527

Roessger, K. M. (2014). The effects of reflective activities on skill adaptation in a work-related instrumental learning setting. Adult Education Quarterly,64(4), 323-344. https://doi.org/10.1177/0741713614539992

Watkins, C. (2001). Learning About learning enhances performance, Institute of Education, National School Improvement Network, Research Matters Series, No 13, London. Retrieved from http://eprints.ioe.ac.uk/2803/1/Watkins2001Learning.pdf

Zheng, L. (2016). The effectiveness of self-regulated learning scaffolds on academic performance in computer-based learning environments: a meta-analysis. Asia Pacific Education Review, 17(2), 187-202. https://doi.org/10.1007/s12564-016-9426-9

Zimmerman, B. J., Moylan, A., Hudesman, J., White, N., \& Flugman, B. (2011). Enhancing selfreflection and mathematics achievement of at-risk urban technical college students. Psychological Test and Assessment Modeling, 53(1), 141-160. Retrieved from http://www.psychologie-aktuell.com/fileadmin/download/ptam/12011_20110328/07_Zimmermann.pdf 